\title{
Genetic polymorphisms and heart failure
}

Gysèle S. Bleumink, $M D^{1,2}$, Anna F.C. Schut, $M D^{1,4}$, Miriam C.J.M. Sturkenboom, PharmD, $P h D^{1}$, Jaap W. Deckers, $M D, P h D^{1,3}$, Cornelia M. van Duijn, $P h D^{1}$, and Bruno H.Ch. Stricker, $P h D^{1,2}$

\begin{abstract}
Heart failure is a complex clinical syndrome. There is evidence for a genetic contribution to the pathophysiology of heart failure. Considering the fundamental role of neurohormonal factors in the pathophysiology and progression of cardiac dysfunction and hypertrophy, variants of genes involved in this system are logical candidate genes in heart failure. In this report, genetic polymorphisms of the major neurohormonal systems in heart failure will be discussed. Studies on polymorphisms of the renin-angiotensin-aldosterone system (RAAS), adrenergic receptor polymorphisms, endothelin (receptor) polymorphisms, and a group of miscellaneous polymorphisms that may be involved in the development or phenotypic expression of heart failure will be reviewed. Research on left ventricular hypertrophy is also included. The majority of genetic association studies focused on the ACE I/D polymorphism. Initial genetic associations have often been difficult to replicate, mainly due to problems in study design and lack of power. Promising results have been obtained with genetic polymorphisms of the RAAS and sympathetic system. Considering the evidence so far, a modifying role for these polymorphisms seems more likely than a role of these variants as susceptibility genes. Besides the need for larger studies to examine the effects of single nucleotide polymorphisms and haplotypes, future studies also need to focus on the complexity of these systems and study gene-gene interactions and gene-environment interactions. Genet Med 2004:6(6):465-474.
\end{abstract}

Heart failure is a complex clinical syndrome with high morbidity and mortality. ${ }^{1,2}$ Impairment of cardiac function activates compensatory neurohormonal mechanisms, which at a later stage may accelerate progression of heart failure. ${ }^{3}$ Coronary heart disease and hypertension are major underlying causes of heart failure. Other frequent underlying conditions include valvular heart disease and idiopathic dilated cardiomyopathy. It is difficult to predict who will develop heart failure in response to myocardial injury. Racial differences in occurrence and outcome of heart failure ${ }^{4,5}$ and heritability estimates of variability in left ventricular mass of $28 \%$ to $65 \%^{6,7}$ suggest a genetic contribution to the pathophysiology of left ventricular remodeling and heart failure.

Many studies have been published on the role of single gene mutations in (familial) cardiomyopathies. ${ }^{8,9}$ These Mendelian traits are by nature rare, and although important at an individual level and for the understanding of disease mechanisms, are of limited significance in terms of prediction of heart failure occurrence in the population. ${ }^{10}$ Moreover, in patients with identical gene mutations clinical manifestations of cardiomy-

\footnotetext{
From the ${ }^{1}$ Department of Epidemiology and Biostatistics, Erasmus Medical Center, Rotterdam, the Netherlands; ${ }^{2}$ Inspectorate for Healthcare, The Hague, the Netherlands; ${ }^{3}$ Department of Cardiology, Erasmus Medical Center, Rotterdam, the Netherlands; and ${ }^{4}$ Department of Internal Medicine, Erasmus Medical Center, Rotterdam, the Netherlands.

Dr. B.H.Ch. Stricker, Department of Epidemiology and Biostatistics, Erasmus Medical Center, PO Box 1738, 3000 DR Rotterdam, the Netherlands.

Received: March 23, 2004

Accepted: June 22, 2004
}

DOI: 10.1097/01.GIM.0000144061.70494.95 opathy may differ. This suggests that probably also environmental and/or other genetic factors play a role.

In this report, genetic polymorphisms of major neurohormonal systems involved in the pathophysiology of heart failure will be discussed, including the renin-angiotensin-aldosterone system (RAAS), adrenergic receptor polymorphisms, endothelin (receptor) polymorphisms, and a group of miscellaneous polymorphisms. Research on left ventricular hypertrophy is also included, because this condition often precedes heart failure. Studies on the association between heart failure and human leukocyte antigen complex alleles and pharmacogenetic studies are outside the scope of this review.

\section{METHODS}

Literature for this report was systematically identified by searching PubMed for all English-language articles published up to July 2003 related to heart failure and genetic polymorphisms. Bibliographies in articles provided further references. A two-step approach was used. First, genetic polymorphisms were identified in a search with the keywords "heart failure" and "polymorphism." Second, polymorphisms that were identified with this search, were used as keywords with the addition of one of the following keywords "heart failure," "left ventricular hypertrophy," "left ventricular mass," and "cardiomyopathy." We focused on genetic association studies.

\section{Heart failure pathophysiology}

Left ventricular dysfunction begins with an injury to the myocardium, e.g., myocardial infarction, which results in loss 
of functional cells. In response, a complex cascade of interacting hemodynamic and neurohormonal mechanisms is activated to preserve cardiac function. ${ }^{3}$ These factors alter the shape and function of the ventricle through a process called left ventricular remodeling, in which fibrosis and myocyte damage appear to be decisive morphological alterations. ${ }^{11,12}$ The most important regulators of this process are components of the RAAS, growth factors, and endocrine hormones such as norepinephrine.

A decreased capacity of the left ventricle to empty during systole increases diastolic wall tension. The ventricle responds by enhanced contraction, following the Frank-Starling curve. ${ }^{13}$ Additionally, the sympathetic nervous system is activated, which provides inotropic support and maintains cardiac output. ${ }^{3}$ Both compensatory mechanisms also lead to increased internal wall stress during diastole. In response, synthesis of myofibrillar proteins is stimulated, resulting in increased wall thickness and a reduction in ventricular wall stress and dilatation. ${ }^{13}$ Sustained sympathetic stimulation, however, activates the RAAS and other neurohormones. The main effector of the RAAS is angiotensin II, a potent vasoconstrictor and stimulator of renal sodium reabsorption and aldosterone and vasopressin release. ${ }^{14}$ Hypoxia, shear stress, and vasoactive hormones also stimulate the generation of endothelin, the most potent endogenous vasoconstrictor. ${ }^{15}$ Endothelin has positive inotropic and chronotropic effects, influences salt and water homeostasis, stimulates the RAAS and sympathetic system and appears to play a role in cardiac remodeling. ${ }^{16}$ With worsening fibrosis and cardiac myocyte degeneration, left ventricular end-diastolic pressure increases and later ejection fraction decreases. ${ }^{12}$

To counterbalance the pressor and volume expanding effects of vasoactive neurohormones, natriuretic peptides are generated, which exert diuretic, natriuretic, and vasodilator properties. ${ }^{17}$ Also, the kallikrein-kinin system forms bradykinin, which results in natriuresis and vasodilatation, and stimulates the production of prostaglandins. ${ }^{3}$ In this way, a delicate hemodynamic balance is achieved, which restores cardiac function temporarily. Long-term activation of these mechanisms, however, results in progressive deterioration of ventricular function.

\section{Genetic polymorphisms}

In common multifactorial diseases, such as heart failure, the candidate gene approach is widely used to study genetic polymorphisms. ${ }^{18}$ This allows for the identification of gene defects directly involved in the pathophysiology of heart failure (susceptibility genes), or variants involved in modification of its phenotypic expression (modifier genes). The case-control study is the most frequently used design. Candidate genes are selected based upon their biological plausibility. Polymorphisms located in coding or promoter regions of a gene may alter the function or expression of proteins encoded by the gene. Even if these polymorphisms are not functional, they are more likely to be in linkage disequilibrium with causative al- leles. ${ }^{10}$ Polymorphisms in intronic enhancer regions, both cis and trans, can also affect expression.

Considering the fundamental role of neurohormonal factors in the pathophysiology and progression of cardiac dysfunction and hypertrophy, variants of neurohormonal genes are logical candidate genes in heart failure. Successively, we will describe the potential role of these variants as susceptibility genes and as modifier genes in heart failure due to ischemic and/or dilated cardiomyopathy and in hypertrophic cardiomyopathy. Also, studies on left ventricular dimensions will be discussed. Table 1 shows genetic polymorphisms that have been associated with one or more of these disease manifestations in at least one study.

\section{Renin-angiotensin-aldosterone system}

The RAAS is one of the major systems involved in the pathophysiology of heart failure. Because it is a complex system, effects of polymorphisms influencing the expression of one of its components may be counterbalanced by compensatory changes in other components. Therefore, for individual mutations, associations are probably modest.

\section{Angiotensin-converting enzyme I/D polymorphism}

ACE enzymatically transforms angiotensin I to angiotensin II. The human ACE gene is located on chromosome 17q23. A genetic polymorphism in intron 16 of this gene is strongly associated with serum levels of ACE. ${ }^{19}$ It is characterized by an insertion (I) or a deletion (D) of a 287 noncoding base pair (bp) Alu repeat sequence. Its functional role has been debated. Probably, this polymorphism is in strong linkage disequilibrium with another functional mutation within the gene..$^{20}$

Raynolds and colleagues ${ }^{21}$ published an association between the ACE I/D polymorphism and heart failure susceptibility in Caucasians. They observed an excess of DD genotype both in subjects with ischemic and idiopathic dilated cardiomyopathy compared to organ donors. However, because their control group was not in Hardy-Weinberg equilibrium, results may have been biased. Subsequently, many conflicting studies followed. A study in 70 Chinese patients appeared to confirm the presence of an association ${ }^{22}$ but was also not in Hardy-Weinberg equilibrium. Most studies did not find an association between the ACE polymorphism and heart failure secondary to ischemic and/or dilated cardiomyopathy in 1506 Caucasian, ${ }^{23-26} 287$ Chinese, ${ }^{27} 281$ Japanese, ${ }^{28}$ and 724 black South African subjects. ${ }^{29,30}$ Hence, it seems unlikely that susceptibility to ischemic or idiopathic dilated cardiomyopathy in the general population is associated with the ACE I/D polymorphism.

In contrast, studies have reported more promising results on the potential role of the ACE polymorphism as a modifier gene in heart failure, at least in Caucasian populations. Andersson found an association between poor survival and DD genotype in 194 Swedish patients with heart failure. ${ }^{31} \mathrm{~A}$ study in 57 white American patients demonstrated that DD genotype was associated with impaired exercise tolerance. ${ }^{32}$ Others found that the $\mathrm{D}$ allele was associated with an increased risk of death or 
Table 1

Genetic polymorphisms that have been associated with heart failure occurrence (susceptibility gene), phenotype (modifier gene), and/or left ventricular structure in genetic association studies

\begin{tabular}{|c|c|c|c|c|c|c|}
\hline Genetic polymorphism & Risk allele $^{a}$ & $\begin{array}{l}\text { Heart failure } \\
\text { occurrence }^{c}\end{array}$ & $\begin{array}{l}\text { Heart failure } \\
\text { phenotype }^{c}\end{array}$ & $\begin{array}{l}\text { DCM/DCM } \\
\text { phenotype }\end{array}$ & $\begin{array}{l}\text { HCM/HCM } \\
\text { phenotype }\end{array}$ & $\begin{array}{c}\text { LVH/LV } \\
\text { dimensions }^{d}\end{array}$ \\
\hline \multicolumn{7}{|c|}{ Renin-angiotensin-aldosterone system } \\
\hline ACE I/D & $\mathrm{D}$ & + & + & + & + & + \\
\hline AGT M235T & $\mathrm{T}$ & + & - & - & + & + \\
\hline AGT-G6A & G & + & - & - & - & + \\
\hline AGT T174M & M & - & - & - & - & + \\
\hline AT1R A1166C & $\mathrm{C}$ & - & + & - & + & $+(\mathrm{A})$ \\
\hline AT2R A3123C & A & - & - & - & + & - \\
\hline AT2R G1675A & A & - & - & - & - & + \\
\hline CYP11B2 C-344T & $\mathrm{C}$ & - & - & + & + & + \\
\hline \multicolumn{7}{|l|}{ Sympathetic system } \\
\hline A2AR $\alpha_{2 \mathrm{c}} \mathrm{Wt} / \mathrm{Del} 322-325$ & Del & + & - & - & - & - \\
\hline B1AR Ser49Gly & Ser & - & + & + & - & - \\
\hline B1AR Arg389Gly & $b$ & - & + & + & - & + \\
\hline B1AR T-2146C & $\mathrm{C}$ & - & - & + & - & - \\
\hline B2AR Arg16Gly & Gly & - & + & - & - & $+(\operatorname{Arg})$ \\
\hline B2AR Gln27Glu & Glu & - & - & - & - & + \\
\hline B2AR Thr164Ile & Ile & - & + & - & - & + \\
\hline \multicolumn{7}{|l|}{ Endothelin } \\
\hline END1 G8002A & A & - & - & - & + & - \\
\hline ETAR C1363T & $\mathrm{T}$ & - & - & + & - & - \\
\hline ETAR C69T & $\mathrm{T}$ & - & - & + & - & - \\
\hline \multicolumn{7}{|l|}{ Miscellaneous } \\
\hline Bradykinin receptor ${ }^{106}$ & +9 & - & - & - & - & + \\
\hline CMA A-1903G G37,42,107 & A & - & - & - & + & + \\
\hline TNF G-308A72,108,109 & A & - & - & + & + & - \\
\hline TGFB1 Leu10Pro ${ }^{110}$ & heterozy & + & - & + & - & - \\
\hline SOD2 Ala16Val"11 & Val & - & - & + & - & - \\
\hline PAF G994T112,113 & $\mathrm{T}$ & - & - & + & + & - \\
\hline CCR2 Val64Ile 114 & Ile & + & - & - & - & - \\
\hline NOS3 Glu298Asp ${ }^{115}$ & Asp & - & + & - & - & - \\
\hline $\mathrm{APOE} \varepsilon 2 / \varepsilon 3 / \varepsilon 4^{116-118}$ & $\varepsilon 4$ & + & - & - & - & + \\
\hline$\alpha$-adducin Gly460Trp ${ }^{58}$ & $\operatorname{Trp}$ & - & - & - & - & + \\
\hline GNB3 C826T119,120 & $\mathrm{T}$ & - & - & - & - & + \\
\hline AMPD1+/-121 & + & - & + & - & - & - \\
\hline
\end{tabular}

${ }^{a}$ In majority studies, ${ }^{b}$ indecisive, $c$ heart failure with multiple causes, not exclusive in DCM or HCM, ${ }^{d}$ in patients without heart failure.

+, at least one positive study; -, no positive association studies; DCM, dilated cardiomyopathy; HCM, hypertrophic cardiomyopathy; LVH, left ventricular hypertrophy; ACE, angiotensin converting enzyme; AGT, angiotensinogen; AT1R, angiotensin II type 1 receptor; AT2R, angiotensin II type 2 receptor; CYP11B2, alodosterone synthase gene; $\alpha 2$-AR, $\alpha 2$-adrenergic receptor; B1AR, $\beta 1$-adrenergic receptor; B2AR, $\beta 2$-adrenergic receptor; END1, endothelin-1; ETAR, endothelin type A receptor; CMA, cardiac chymase; TNF, tumor necrosis factor $\alpha$; TGFB1, transforming growth factor $\beta$-1; SOD, superoxide dismutase; PAF, platelet-activating factor; CCR, chemokine receptor; NOS, nitric oxide synthase; APOE, apolipoprotein E; GNB3, G-protein $\beta 3$ subunit; AMPD1, adenosine monophosphate deaminase 1 . 
heart transplantation in 328 American patients. ${ }^{33}$ Two small studies in 90 Czech and 84 Turkish subjects did, however, not detect an association between heart failure phenotype and ACE genotype. ${ }^{24,26}$ Studies in Japanese $e^{28,34}$ and Chinese patients ${ }^{35}$ failed to associate this polymorphism with heart failure phenotype, whereas studies in blacks were contradictory. Candy et al. ${ }^{30}$ found an association between DD genotype and reduced cardiac function and increased cavity size in South African patients with cardiomyopathy, whereas others did not. ${ }^{29}$

The first study on the ACE polymorphism and hypertrophic cardiomyopathy found an excess of DD genotype in Caucasian patients, especially in families with a history of sudden cardiac death. ${ }^{36}$ Other studies have since then confirmed the higher frequency of DD genotype in hypertrophic cardiomyopathy in white and Japanese patients. ${ }^{37-39}$ Yamada et al. ${ }^{28}$ did not detect an association between ACE genotypes and hypertrophic cardiomyopathy in Japanese. In addition, no association was found between ACE genotypes and echocardiographic measurements. Also, a study in 104 Dutch patients did not support a role for the I/D polymorphism as a modifier in this disorder. ${ }^{40}$ An association of ACE genotype with phenotypic expression of hypertrophic cardiomyopathy was, however, observed in Caucasians by others. ${ }^{41} \mathrm{~A}$ study conducted in a family affected by a single mutation in the myosin binding protein- $\mathrm{C}$ (MyBP-C) gene confirmed these results. ${ }^{42}$ It seems that the influence of ACE genotype in patients with hypertrophic cardiomyopathy depends on the specific disease-causing mutation, which may offer an explanation for the conflicting results. ${ }^{43}$ Similar to ischemic and idiopathic dilated cardiomyopathy, it is more likely that the ACE I/D polymorphism acts as a modifier in hypertrophic cardiomyopathy than as a susceptibility gene.

Many studies have investigated the influence of the ACE polymorphism on left ventricular hypertrophy. There is considerable controversy on this topic. Schunkert and colleagues described an association between DD genotype and electrocardiographic left ventricular hypertrophy in 1428 Europeans. ${ }^{44}$ Another large-scale investigation was performed in the Framingham Heart Study in 2439 subjects..$^{45}$ No association was found between ACE genotypes and echocardiographic left ventricular hypertrophy. Kuznetsova et al. ${ }^{46}$ have summarized the majority of studies ( $n=28$, overall sample size 6638) in a metaanalysis. There was significant heterogeneity among studies and the definition of left ventricular hypertrophy varied widely. Using data from 12 case-control studies, the pooled odds ratio (OR) of left ventricular hypertrophy with presence of the D allele was 1.09 [95\% confidence interval (CI) $0.98-$ 1.21]. Subgroup analyses, however, showed that in untreated hypertensives, the risk of cardiac hypertrophy for the DD genotype compared to the II genotype was significantly increased (OR 2.92; 95\% CI 1.50-5.70). Also, left ventricular mass as a continuous trait was only associated with ACE genotype in never-treated hypertensives. Therefore, findings suggest that the ACE polymorphism may only have an impact on cardiac dimensions in hypertensives. From a clinical perspective, one might speculate that this effect can be neutralized by the use of antihypertensive drugs. Although there are many studies on the ACE I/D polymorphism, study populations are often not in Hardy-Weinberg equilibrium. There may be various explanations, including differential mortality, but also genotyping error cannot be excluded. This calls for a different approach in which multiple markers are tested that are more robust than the original ACE I/D variant.

\section{Angiotensinogen M235T polymorphism}

Angiotensinogen is converted to angiotensin I. The human angiotensinogen gene is located on chromosome 1q42-43.47 Three polymorphisms have been studied: two mutations in exon 2 resulting in a methionine to threonine exchange at position 235 (M235T) and a threonine to methionine substitution at position $174(\mathrm{~T} 174 \mathrm{M})$, and a G-6A variant, which represents a guanine to adenine substitution $6 \mathrm{bp}$ upstream from the initiation site of transcription in the promoter region. ${ }^{48}$ The G-6A variant is in close linkage disequilibrium with the M235T polymorphism and will not be discussed separately. As the T174M variant has been studied only once with respect to cardiac dimensions ${ }^{49}$ we focus on the $\mathrm{M} 235 \mathrm{~T}$ polymorphism.

The $235 \mathrm{~T}$ allele is associated with a stepwise increase in angiotensinogen levels and with a moderate increase in risk of hypertension..$^{50}$ Nevertheless, most studies did not find an association between the M235T polymorphism and development or progression of ischemic and dilated cardiomyopathy. ${ }^{25,28,29,35}$ Therefore, it is unlikely that this polymorphism plays a role in these disorders. An increased risk of heart failure in subjects carrying both $235 \mathrm{M} / \mathrm{T}$ and $-6 \mathrm{G} / \mathrm{G}$ genotypes has been reported, however, suggesting the presence of a diseaserelated haplotype. ${ }^{51}$

In hypertrophic cardiomyopathy, conflicting findings have been published. In Japanese subjects, one study revealed a higher frequency of the 235T allele in hypertrophic cardiomyopathy. ${ }^{38}$ This could not be confirmed by others. ${ }^{28}$ A study by Ortlepp and colleagues in 26 family members carrying a single mutation in the MyBP-C gene revealed a significant association between the angiotensinogen polymorphism and cardiac hypertrophy. ${ }^{42}$ In contrast, the extent of hypertrophy in 108 unrelated Canadian patients was not influenced by angiotensinogen genotype. ${ }^{52}$

Most studies on left ventricular hypertrophy have been performed in Caucasians. ${ }^{48,49,53-58}$ The majority did not find an association. ${ }^{49,54-58}$ In contrast, studies in Chinese dialysis patients, ${ }^{59}$ South Korean patients with chest discomfort or hypertension ${ }^{60}$ and Japanese outpatients of a cardiovascular clinic ${ }^{61}$ found an association between TT genotype and cardiac hypertrophy. This suggests a more important role for the M235T polymorphism in Asian populations, corresponding with a higher frequency of the $\mathrm{T}$ allele in these populations. ${ }^{35} \mathrm{~A}$ study in 103 Japanese patients, however, did not show an association between this polymorphism and left ventricular remodeling after myocardial infarction. ${ }^{62}$ 


\section{Angiotensin II receptor polymorphisms}

The gene for human angiotensin II type 1 receptor $\left(\mathrm{AT}_{1} \mathrm{R}\right)$ is located on chromosome 3. Stimulation of the $\mathrm{AT}_{1} \mathrm{R}$ results in vasoconstriction, increased atherogenicity, inflammation, growth, proliferation, or coagulation, depending on local conditions. ${ }^{63}$ In chronic heart failure, the $\mathrm{AT}_{1} \mathrm{R}$ is downregulated in the heart. Various polymorphisms have been detected in this receptor, of which an adenine/cytosine (A/C) substitution located at position 1166 has been associated with heart failure and cardiac dimensions. This variant is probably not functional. ${ }^{40}$ The $\mathrm{C}$ allele is considered to be the risk allele.

A potential interaction between ACE DD and AT1R AC/CC genotypes was described as a predictor of survival in Swedish patients with heart failure. ${ }^{31} \mathrm{~A}$ large study in a French population (CARDIGENE study) failed to detect an association between the $\mathrm{AT}_{1} \mathrm{R}$ polymorphism and idiopathic dilated cardiomyopathy. ${ }^{25}$ This study, however, used unconditional analyses despite matching of cases and controls on gender and agedistribution. Sanderson and colleagues ${ }^{35}$ did find an association between clinical course of heart failure and the $\mathrm{C}$ allele in 82 Chinese patients.

One study has been performed on hypertrophic cardiomyopathy in Japanese subjects. Although there was a significant difference in allele frequencies between patients and relatives, no difference in genotype frequencies was found between patients and healthy controls. ${ }^{64}$ However, controls were not in Hardy-Weinberg equilibrium, which may have biased the results, and statistical analysis was performed unconditional, despite matching on age and gender. Two studies in Caucasian populations also found no association between the $\mathrm{AT}_{1} \mathrm{R}$ polymorphism and occurrence of hypertrophic cardiomyopathy. ${ }^{40,52}$ Some studies showed that the $1166 \mathrm{C}$ allele might adversely affect the phenotypic expression of hypertrophic cardiomyopathy. ${ }^{40,42}$ Therefore, A1166C polymorphism does not seem to increase heart failure susceptibility, but may play a modifying role. As only one out of six studies found an association between this variant and cardiac hypertrophy, a role for the A1166C polymorphism in left ventricular remodeling seems unlikely, at least in Caucasians. Moreover, this positive study was small, and unexpectedly, the A allele was more frequent in cases. ${ }^{53}$

The angiotensin II type 2 receptor $\left(\mathrm{AT}_{2} \mathrm{R}\right)$ gene is located on the $\mathrm{X}$ chromosome. The $\mathrm{AT}_{2} \mathrm{R}$ probably counteracts the effects of $\mathrm{AT}_{1} \mathrm{R}^{63}$ Deinum investigated the association between a polymorphism in exon $3\left(\mathrm{~A} 3123 \mathrm{C}\right.$ ) of the $\mathrm{AT}_{2} \mathrm{R}$ gene and extent of hypertrophy in 103 Dutch patients with hypertrophic cardiomyopathy. The extent of echocardiographic hypertrophy decreased with the number of $\mathrm{C}$ alleles in women. ${ }^{65} \mathrm{~A}$ potential interaction between $\mathrm{AT}_{1} \mathrm{R} A 1166 \mathrm{C}$ and $\mathrm{AT}_{2} \mathrm{R}$ A3123C polymorphisms was detected in men only.

Erdmann and colleagues ${ }^{66}$ found no significant differences between allele frequencies of a G1675A polymorphism in intron 1 of the $\mathrm{AT}_{2} \mathrm{R}$ in 107 patients with hypertrophic cardiomyopathy, 95 patients with dilated cardiomyopathy, and 160 normal controls. In 120 young white males, however, an asso- ciation between the $1675 \mathrm{~A}$ allele and structural cardiac changes was found in mildly hypertensive persons. ${ }^{67}$ Two independent studies on left ventricular hypertrophy in Glasgow residents showed inconsistent results. ${ }^{68}$ As the G1675A polymorphism is located in a gene region that is involved in the transcriptional control of the $\mathrm{AT}_{2} \mathrm{R}$ gene, this variant is potentially functional. ${ }^{67,68}$ Therefore, more studies are needed to determine the role of this polymorphism in heart failure.

\section{Aldosterone synthase C-344T polymorphism}

Aldosterone excess is a well-documented cause of hypertension and there is convincing evidence that mineralocorticoids have adverse effects in heart failure. ${ }^{69}$ The key enzyme in aldosterone synthesis is aldosterone synthase. The corresponding gene CYP11B2 is located on chromosome $8 .^{70} \mathrm{~A}$ cytosine/thymidine $(\mathrm{C} / \mathrm{T})$ substitution in the 5 ' promoter region at location -344 of the CYP11B2 gene has been identified. The functionality of this variant is unclear. ${ }^{70} \mathrm{Few}$ studies have described the association between heart failure and C-344T polymorphism. Studies in Caucasian and Japanese patients did not find an association between this variant and idiopathic dilated cardiomyopathy. ${ }^{25,71}$ However, the $\mathrm{C}$ allele was associated with increased left ventricular volume in the Japanese patients. ${ }^{71}$ This finding could not be confirmed in black South Africans with heart failure. ${ }^{29}$ Studies in hypertrophic cardiomyopathy also yielded conflicting results. ${ }^{42,72}$ Consequently, there is no firm evidence for a role of this polymorphism in heart failure.

An association between the C-344T variant and left ventricular hypertrophy was detected in young healthy Finns. ${ }^{73} \mathrm{Al}-$ though one small study confirmed this association, ${ }^{74}$ other larger studies failed to detect a significant effect of this polymorphism on left ventricular structure. ${ }^{75,76}$ Mayosi et al. ${ }^{77}$ investigated the contribution of several markers in the CYP11B2 gene, including the $\mathrm{C}-344 \mathrm{~T}$ polymorphism, as individual variants and haplotypes. Polymorphisms and haplotypes at the CYP11B2 locus were associated with a small but significant effect on variation in septal wall thickness and left ventricular cavity size (variants G5937C and A4450C respectively). No significant association was detected with cardiac mass.

\section{Sympathetic system}

Adrenergic receptors are divided into $\alpha$ - and $\beta$-adrenergic receptors. $\alpha_{1}$-Adrenergic receptors are mediators of cardiomyocyte hypertrophy, whereas $\alpha_{2}$-adrenergic receptors are presynaptic inhibitors of norepinephrine release. ${ }^{78} \beta_{1^{-}}$and $\beta_{2^{-}}$ adrenergic receptors increase cardiac inotropy and chronotropy, the $\beta_{1}$-receptor being the dominant subtype. ${ }^{79}$ In heart failure, chronic sympathetic activation leads to selective downregulation of $\beta_{1}$-adrenergic receptors and uncoupling of $\beta_{1^{-}}$and $\beta_{2}$-adrenergic receptors, markedly blunting both signaling pathways. ${ }^{78}$ Therefore, one may hypothesize that genetic variants of adrenergic receptors play a role in heart failure. In addition, $\beta$-adrenergic receptor blockers have been found to improve symptoms and mortality in heart failure, albeit with substantial interindividual variation. ${ }^{79}$ 


\section{$\alpha_{\mathbf{2}}$-Adrenergic receptor Del322-325 polymorphism}

The Del322-325 polymorphism in the gene for the $\alpha_{2 c}$-adrenergic receptor, located on chromosome 4 and leading to the deletion of four consecutive amino acids, causes a substantial loss of agonist-mediated receptor function in vitro. ${ }^{80}$ So far, only one study addressed the potential role of this polymorphism in heart failure susceptibility. Small et al ${ }^{81}$ found that black subjects who were homozygous for the $\alpha_{2 \mathrm{c}}$ Del322-325 variant were more than 5 times as likely to have heart failure as those who were not. A two-locus analysis indicated a significant interaction between the $\alpha_{2 c}$ Del322-325 polymorphism and the 389Arg variant of the $\beta_{1}$-adrenergic receptor. Although not significant, associations for white subjects were similar in magnitude and direction. The $\alpha_{2 \mathrm{c}}$ Del322-325 variant was more than 10 times more common in black than in white controls. As this polymorphism potentially changes the functionality of the $\alpha_{2 c}$-adrenergic receptor, it is an important candidate for further research on genetic factors in heart failure.

\section{$\boldsymbol{\beta}_{\mathbf{1}}$-Adrenergic receptor polymorphisms}

Two major polymorphic loci have been identified in the gene coding for the $\beta_{1}$-adrenergic receptor located on chromosome 10. A guanine/cytosine substitution at nucleotide 1165 produces a change in the amino acid sequence, substituting a glycine (Gly) for an arginine (Arg) residue at position 389. This residue lies within the intracellular carboxy-terminus that is critical for G-protein coupling. Data indicate that this polymorphism has functional consequences for intracellular signaling. ${ }^{82}$ The second variant, an adenine/guanine substitution at nucleotide position 145 , results in a serine (Ser) or glycine (Gly) at amino acid $49 .{ }^{83}$ Genetic variation in this residue has been shown in vitro to affect receptor desensitization and agonist-dependent down-regulation. ${ }^{84}$ So, both polymorphic loci may lead to functional changes of the $\beta_{1}$-adrenergic receptor and hence both may play a role in heart failure. Genetic association studies, however, have been contradictory.

In the CARDIGENE study, no association was found between the Arg389Gly polymorphism and idiopathic dilated cardiomyopathy and disease severity. ${ }^{85}$ Others have confirmed the lack of an association with heart failure occurrence. ${ }^{34,81,86}$ Small and colleagues ${ }^{81}$ did find a significant interaction between the $\alpha_{2 \mathrm{c}}$ Del322-325 variant and the $\beta_{1} \operatorname{Arg} 389$ allele in heart failure susceptibility. An impaired exercise performance was demonstrated in patients with ischemic or idiopathic dilated cardiomyopathy, who were homozygous for Gly389 compared to Arg389 homozygotes, with an intermediate level of performance in heterozygotes. ${ }^{87}$ This may suggest a role for the Arg389Gly polymorphism as a disease modifier. Also, a study in patients with renal disease found higher cardiac mass in Gly389 homozygotes. ${ }^{88}$ In contrast, a study in Japanese cardiomyopathy patients showed a protective effect of the Gly389 allele in susceptibility to ventricular tachycardia. ${ }^{34}$

Few studies have been published on the Ser49Gly polymorphism. A study in dilated cardiomyopathy demonstrated that
5 -year transplant-free survival was worse in Ser49 homozygotes than in patients with the Ser49Gly variant. ${ }^{83}$ Allele frequencies in patients did not differ from those in normal controls. Another study found impaired exercise capacity in patients with ischemic or dilated cardiomyopathy homozygous for the Ser 49 allele compared to Gly 49 carriers. ${ }^{87}$ In contrast, Podlowski and colleagues ${ }^{86}$ only found the Gly 49 mutation in patients with idiopathic dilated cardiomyopathy and not in healthy volunteers.

One other polymorphic locus in the gene for the $\beta_{1}$-adrenergic receptor, T-2146C, has been associated with idiopathic dilated cardiomyopathy. ${ }^{89}$ Thus far, there is not enough evidence to draw firm conclusions about the role of $\beta_{1}$-adrenergic receptor polymorphisms in heart failure.

\section{$\boldsymbol{\beta}_{\mathbf{2}}$-Adrenergic receptor polymorphisms}

An intronless gene on chromosome 5 encodes the $\beta_{2}$-adrenergic receptor. Attention has focused on three polymorphisms that display altered receptor function in experimental studies. ${ }^{79,90}$ The most functionally altered receptor is due to a threonine (Thr) to isoleucine (Ile) switch at amino acid 164. This rare variant receptor exhibits abnormal coupling to stimulatory G-protein. ${ }^{91}$ The other two polymorphic loci occur on amino acid positions 16 [arginine (Arg)/glycine (Gly) substitution] and 27 [glutamine (Gln)/glutamic acid (Glu) substitution]. ${ }^{90}$ There is marked linkage disequilibrium between these two polymorphisms..$^{92}$ The Gly16 receptor displays enhanced agonist-promoted downregulation, whereas the Glu27 form is resistant to downregulation..$^{90,93}$

Two studies have investigated the effect of $\beta_{2}$-adrenergic polymorphisms in heart failure. Especially the Thr164Ile variant seems to be important in its phenotypic expression. The first study found no difference in frequency of the three polymorphisms between heart failure patients and normal subjects. ${ }^{90}$ However, patients who were heterozygous for the Ile164 mutation had significantly worse survival than homozygous Thr164 patients. Trends for Arg16Gly and Gln27Glu did not reach statistical significance. The second study demonstrated that patients with heart failure carrying the Ile164 allele had a lower exercise capacity than patients homozygous for Thr164. ${ }^{44}$ Patients homozygous for the Gly16 allele also demonstrated lower exercise capacity than Arg16 homozygotes. As the Thr164Ile variant is rare, both studies did not include homozygous Ile164 subjects. A study in normotensive twins indicated that all three polymorphisms might be associated with ventricular wall thickness..$^{92}$ However, other studies have failed to detect any association between the Arg16Gly and Gln27Glu polymorphisms and cardiac dimensions. ${ }^{95-97}$ These studies did not investigate the role of the Thr164Ile variant.

\section{Endothelin}

There is considerable evidence to support a role for the endothelin system in heart failure. ${ }^{98}$ The endothelin A receptor mainly mediates the vasoconstrictor effects of endothelin-1, the predominant endothelin isoform. The endothelin B receptor has similar affinity for all isoforms and mediates vasodila- 
tation in endothelial cells and vasoconstriction in smooth muscle cells. ${ }^{16}$ Few genetic association studies have been performed.

Studies on dilated cardiomyopathy did not detect a role of genetic polymorphisms in the endothelin-1 gene. ${ }^{99,100}$ Brugada and colleagues showed that a G8002A polymorphism located in the 4th intron of the endothelin-1 gene on chromosome 6 might act as a modifier gene in hypertrophic cardiomyopathy. ${ }^{52}$ Two variants of the endothelin A receptor have been studied with promising results. In the CARDIGENE study, a cytosine/thymidine (C/T) substitution in exon 8 at nucleotide position 1363 was associated with idiopathic dilated cardiomyopathy. ${ }^{99}$ Individuals homozygous for the T allele were at significantly increased risk for this disease. A C/T substitution in exon 6 at position 69, which does not alter the amino acid sequence of the receptor, has been associated with survival inpatients with nonischemic dilated cardiomyopathy. ${ }^{100}$ Carriers of the $\mathrm{T}$ allele had a more than 5 -fold increased risk of death within 2 years after the diagnosis. A study in 528 never-treated hypertensives demonstrated that variants in the genes encoding endothelin- 1 and the endothelin A receptor are not significant determinants of cardiac morphometric parameters. ${ }^{101}$ Although several studies also investigated the role of endothelin B receptor polymorphisms, no significant associations were found. ${ }^{99-101}$

\section{Miscellaneous genetic polymorphisms}

Multiple other polymorphisms have been investigated in heart failure, with variable success. These are mainly genetic variants of factors that play a role in cardiac remodeling, inflammation, signal transduction, or protection from oxidative damage. Genetic polymorphisms that have been associated with heart failure, heart failure phenotype, and/or left ventricular structure are presented in Table 1. However, few studies have been published for most of these variants and their exact role in heart failure susceptibility and modification needs to be elucidated further.

\section{DISCUSSION}

There is substantial evidence that genes play a role in the pathophysiology of heart failure. Numerous studies have investigated the association of heart failure with polymorphisms in candidate genes. Even more studies examined the role of genetic variants in left ventricular hypertrophy. Most studies focused on the ACE I/D polymorphism. In addition, genetic polymorphisms have been studied of other RAAS components, adrenergic receptors, endothelin-1, and endothelin receptors and of factors that play a role in cardiac remodeling, inflammation, signal transduction, or protection of cells from oxidative damage. Still, many genes in heart failure remain to be discovered. So far, genetic association studies in heart failure and cardiac remodeling have been highly inconsistent. As heart failure is a complex trait, there are probably several genetic variants that together result in the expression of its pathological phenotype. ${ }^{79}$ Therefore, for individual polymorphisms, associations are likely to be modest. The same holds for variants associated with cardiac hypertrophy. The ultimate evidence of these genetic polymorphisms being more than just risk markers depends on the characterization of intermediate phenotypes that can be linked to the disease. ${ }^{102}$ Because most studies on heart failure susceptibility did not find an association, a role for neurohormonal polymorphisms as modifier genes seems more likely.

Genetic associations that were found in initial studies have often been difficult to reproduce. There are several potential explanations for this. The major problem has been lack of power to detect the typically small effects in genetic association studies of multifactorial traits. ${ }^{103}$ Besides increasing the sample size of a study population, this problem may be resolved by studying the combination of several genetic markers into haplotypes. ${ }^{77}$ Small studies with statistically significant associations are more readily published. This may overestimate the true effect. Several studies used unconditional statistical methods for data analysis, despite the fact that they matched their cases and controls on population characteristics. $25,31,34,37,64,71,85$ This may underestimate the effect of the polymorphisms studied, as it will bias the results toward the null hypothesis.

An association between a genetic polymorphism and a disease (phenotype) may merely be caused by its linkage disequilibrium with a mutation of a nearby gene that is the actual functional gene. Patterns of linkage disequilibrium can vary significantly within and between populations due to several factors, including population admixture and age of the mutation. ${ }^{18}$ If a polymorphism is not functional, varying degrees of linkage disequilibrium may explain variations between populations. Much emphasis has been put on the role of population stratification in the generation of false-positive results. When the population under study consists of a mixture of subpopulations that have different allele frequencies and disease risks, genetic associations can be confounded by population stratification. ${ }^{103}$ The most important confounder in this respect is ethnicity. Frequency and outcome of heart failure differ significantly between races, ${ }^{4,5}$ as do allele frequencies of genetic polymorphisms. ${ }^{28,35,38,80}$ Nearly all populations are confounded by genetic admixture at some level. ${ }^{104}$ Lack of replicability of an association in different ethnic groups does not rule out the possibility of a causal association, because of potentially different background risks, allele frequencies, and environmental factors. Genotyping error may also affect the results of genetic association studies and is the most common cause of deviations from the Hardy-Weinberg equilibrium. An important example of this type of exposure misclassification is the underestimation of ACE I/D heterozygotes that may occur with the conventional genotyping method. ${ }^{105}$ Most studies on heart failure used this non-I-allele-specific method for ACE genotyping may have underestimated the effect of the DD genotype. In addition, large heterogeneity in outcome measures between studies may account for contradictory findings.

\section{Clinical application}

This review raises the question whether a clinical geneticist's evaluation is indicated for predicting the occurrence of heart 
failure in an individual. The general answer is no, as there is too little known currently about the role of susceptibility genes in heart failure, except for single gene mutations associated with the familial cardiomyopathies. Familial cardiomyopathies are usually detected through the clinical setting, an echocardiogram, and the presence of a family history showing dominant inheritance. ${ }^{122,123}$ An extended family pedigree for a patient with heart failure not associated with a familial cardiomyopathy may be useful in the research setting but has no place in general medical care, and referral to a genetics clinic for this type of heart failure is not warranted at the present time. Furthermore, testing for the various genetic polymorphisms discussed in this review is not indicated in the routine evaluation of a patient with heart failure not associated with a cardiomyopathy. As a result, it will be difficult to provide accurate and knowledgeable genetic counseling for most heart failure patients not associated with a familial cardiomyopathy.

In summary, genetic association studies on heart failure and cardiac remodeling have focused on polymorphisms that may influence neurohormonal factors. Initial genetic associations have often been difficult to replicate, mainly due to faulty study designs and lack of power. Most promising results have been obtained with polymorphisms of RAAS and sympathetic system. A role for these polymorphisms as modifier rather than susceptibility genes seems more likely considering the evidence so far. Heart failure is probably caused by many genetic factors that are all components of larger complex systems and interact with environmental factors. Besides the need for larger studies to examine the effects of single genetic variants and haplotypes, future studies also need to focus on the complexity of these systems and study gene-gene interactions and gene-environment interactions. ${ }^{100-121}$

\section{References}

1. Remme WJ, Swedberg K. Guidelines for the diagnosis and treatment of chronic heart failure: Task Force for the diagnosis and treatment of chronic heart failure, European Society of Cardiology. Eur Heart J 2001;22:1527-1560.

2. Kannel WB. Vital epidemiologic clues in heart failure. J Clin Epidemiol 2000;53: $229-235$.

3. Jackson G, Gibbs CR, Davies MK, Lip GYH. ABC of heart failure. Pathophysiology. BMJ 2000;320:167-170.

4. Dries DL, Exner DV, Gersh BJ, Cooper HA, Carson PE, Domanski MJ. Racial differences in the outcome of left ventricular dysfunction. N Engl J Med 1999;340: 609-616.

5. Blackledge HM, Newton J, Squire I. Prognosis for South Asian and white patients newly admitted to hospital with heart failure in the United Kingdom: historical cohort study. BMJ 2003;327:526-532.

6. Garner C, Lecomte E, Visvikis S, Abergel E, Lathrop M, Soubrier F. Genetic and environmental influences on left ventricular mass. A family study. Hypertension 2000;36:740-746.

7. Kotchen TA, Kotchen JM, Grim CE et al. Genetic determinants of hypertension. Identification of candidate phenotypes. Hypertension 2000;36:7-13.

8. Towbin JA, Bowles NE. The failing heart. Nature 2002;415:227-233.

9. Franz WM, Muller OJ, Katus HA. Cardiomyopathies: from genetics to prospect of treatment. Lancet 2001;358:1627-1637.

10. Risch NJ. Searching for genetic determinants in the new millennium. Nature 2000; 405:847-856.

11. Jessup M, Brozena S. Heart failure. N Engl J Med 2003;348:2007-2018.

12. Hein S, Arnon E, Kostin S et al. Progression from compensated hypertrophy to failure in the pressure-overloaded human heart. Circulation 2003;107:984-991.

13. Packer M. Pathophysiology of chronic heart failure. Lancet 1992;340:88-92.

14. Unger $\mathrm{T}$. The role of the renin-angiotensin system in the development of cardiovascular disease. Am J Cardiol 2002;89:3A-9A.
15. Levin ER. Endothelins. N Engl J Med 1995;333:356-363.

16. Giannessi D, Del Ry S, Vitale RL. The role of endothelins and their receptors in heart failure. Pharmacol Res 2001;43:111-126.

17. Baughman KL. B-type natriuretic peptide-a window to the heart. N Engl J Med 2002;347:158-159.

18. Cardon LR, Bell JI. Association study designs for complex diseases. Nat Rev Genet 2001;2:91-99.

19. Rigat B, Hubert C, Alhenc-Gelas F et al. An insertion/deletion polymorphism in the angiotensin I-converting enzyme gene accounting for half the variance of serum enzyme levels. J Clin Invest 1990;86:1343-1346.

20. Niu T, Chen X, Xu X. Angiotensin converting enzyme gene insertion/deletion polymorphism and cardiovascular disease. Therapeutic implications. Drugs 2002; 62:977-993.

21. Raynolds MV, Bristow MR, Bush EW et al. Angiotensin-converting enzyme DD genotype in patients with ischaemic or idiopathic dilated cardiomyopathy. Lancet 1993;342:1073-1075.

22. Harn HJ, Chang CY, Ho LI et al. Evidence that polymorphism of the angiotensin I converting enzyme gene may be related to idiopathic dilated cardiomyopathy in the Chinese population. Biochem Mol Biol Int 1995;35:1175-1181.

23. Montgomery HE, Keeling PJ, Goldman JH et al. Lack of association between the insertion/deletion polymorphism of the angiotensin-converting enzyme gene and idiopathic dilated cardiomyopathy. J Am Coll Cardiol 1995;25:1627-1631.

24. Vančura V, Hubáček J, Málek I et al. Does angiotensin-converting enzyme polymorphism influence the clinical manifestation and progression of heart failure in patients with dilated cardiomyopathy? Am J Cardiol 1999;83:461-462.

25. Tiret L, Mallet C, Poirier O et al. Lack of association between polymorphisms of eight candidate genes and idiopathic dilated cardiomyopathy. The CARDIGENE Study. J Am Coll Cardiol 2000;35:29-35.

26. Akbulut T, Bilsel T, Terzi S et al. Relationship between ACE gene polymorphism and ischemic chronic heart failure in Turkish population. Eur J Med Res 2003;8: 247-253.

27. Sanderson JE, Young RP, Yu CM et al. Lack of association between insertion/ deletion polymorphism of the angiotensin-converting enzyme gene and end-stage heart failure due to ischemic or idiopathic dilated cardiomyopathy in the Chinese. Am J Cardiol 1996;77:1008-1010.

28. Yamada Y, Ichihara S, Fujimura T, Yokota M. Lack of association of polymorphisms of the angiotensin converting enzyme and angiotensinogen genes with nonfamilial hypertrophic or dilated cardiomyopathy. Am J Hypertens 1997;10:921-928.

29. Tiago AD, Badenhorst D, Skudicky D et al. An aldosterone synthase gene variant is associated with improvement in left ventricular ejection fraction in dilated cardiomyopathy. Cardiovasc Res 2002;54:584-589.

30. Candy GP, Skudicky D, Mueller UK, et al. Association of left ventricular systolic performance and cavity size with angiotensin-converting enzyme genotype in idiopathic dilated cardiomyopathy. Am J Cardiol 1999;83:740-744.

31. Andersson B, Blange I, Sylvén C. Angiotensin-II type 1 receptor gene polymorphism and long-term survival in patients with idiopathic congestive heart failure. Eur J Heart Fail 1999;1:363-369.

32. Abraham MR, Olson LJ, Joyner MJ et al. Angiotensin-converting enzyme genotype modulates pulmonary function and exercise capacity in treated patients with congestive stable heart failure. Circulation 2002;106:1794-1799.

33. McNamara DM, Holubkov R, Janosko K et al. Pharmacogenetic interactions between $\beta$-blocker therapy and the angiotensin-converting enzyme deletion polymorphism in patients with congestive heart failure. Circulation 2001;103:16441648.

34. Iwai C, Akita H, Shiga $N$ et al. Suppressive effect of the Gly389 allele of the $\beta_{1^{-}}$ adrenergic receptor gene on the occurrence of ventricular tachycardia in dilated cardiomyopathy. Circ J 2002;66:723-728.

35. Sanderson JE, Yu CM, Young RP et al. Influence of gene polymorphisms of the renin-angiotensin system on clinical outcome in heart failure among the Chinese. Am Heart J 1999;137:653-657.

36. Marian AJ, Yu QT, Workman R, Greve G, Roberts R. Angiotensin-converting enzyme polymorphism in hypertrophic cardiomyopathy and sudden cardiac death. Lancet 1993;342:1085-1086.

37. Pfeufer A, Osterziel KJ, Urata $\mathrm{H}$ et al. Angiotensin-converting enzyme and heart chymase gene polymorphisms in hypertrophic cardiomyopathy. Am J Cardiol 1996;78:362-364.

38. Ishanov A, Okamoto $\mathrm{H}$, Yoneya $\mathrm{K}$ et al. Angiotensinogen gene polymorphism in Japanese patients with hypertrophic cardiomyopathy. Am Heart J 1997;133:184189.

39. Yoneya K, Okamoto H, Machida M et al. Angiotensin-converting enzyme gene polymorphism in Japanese patients with hypertrophic cardiomyopathy. Am Heart J 1995;130:1089-1093. 
40. Osterop APRM, Kofflard MJM, Sandkuijl LA et al. AT 1 receptor A/C ${ }^{1166}$ polymorphism contributes to cardiac hypertrophy in subjects with hypertrophic cardiomyopathy. Hypertension 1998;32:825-830.

41. Lechin M, Quinones MA, Omran A, et al. Angiotensin-I converting enzyme genotypes and left ventricular hypertrophy in patients with hypertrophic cardiomyopathy. Circulation 1995;92:1808-1812.

42. Ortlepp JR, Vosberg HP, Reith S et al. Genetic polymorphisms in the renin-angiotensin-aldosterone system associated with expression of left ventricular hypertrophy in hypertrophic cardiomyopathy: a study of five polymorphic genes in a family with a disease causing mutation in the myosin binding protein $\mathrm{C}$ gene. Heart 2002;87:270-275.

43. Tesson F, Dufour C, Moolman JC et al. The influence of the angiotensin I converting enzyme genotype in familial hypertrophic cardiomyopathy varies with the disease gene mutation. J Mol Cell Cardiol 1997;29:831-838.

44. Schunkert H, Hense HW, Holmer SR et al. Association between a deletion polymorphism of the angiotensin-converting-enzyme gene and left ventricular hypertrophy. N Engl J Med 1994;330:1634-1638.

45. Lindpaintner K, Lee M, Larson MG et al. Absence of association or genetic linkage between the angiotensin-converting-enzyme gene and left ventricular mass. NEngl J Med 1996;334:1023-1028.

46. Kuznetsova T, Staessen JA, Wang JG et al. Antihypertensive treatment modulates the association between the ACE I/D polymorphism and left ventricular hypertrophy: a meta-analysis. J Hum Hypertens 2000;14:447-454.

47. Davis GK, Roberts DH. Molecular genetics of the renin-angiotensin system: implications for angiotensin II receptor blockade. Pharmacol Ther 1997;75:43-50.

48. Tang W, Devereux RB, Oberman A, Hopkins PN, Kitzman DW, Arnett DK. Associations between angiotensinogen gene variants and left ventricular mass and function in the HyperGEN study. Am Heart J 2002;143:854-860.

49. Wong KK, Summers KM, Burstow DJ, West MJ. Angiotensin-converting enzyme and angiotensinogen genes in patterns of left ventricular hypertrophy and in diastolic dysfunction. Clin Exp Pharmacol Physiol 1995;22:438-440.

50. Sethi AA, Nordestgaard BG, Hansen AT. Angiotensinogen gene polymorphism, plasma angiotensinogen, and risk of hypertension and ischemic heart disease. A meta-analysis. Arterioscler Thromb Vasc Biol 2003;23:1269-1275.

51. Goldbergova M, Spinarova L, Spinar J, Toman J, Vasku A, Vacha J. Association of two angiotensinogen gene polymorphisms, M235T and G(-6)A, with chronic heart failure. Int J Cardiol 2003;89:267-272.

52. Brugada R, Kelsey W, Lechin $\mathrm{M}$ et al. Role of candidate modifier genes on the phenotypic expression of hypertrophy in patients with hypertrophic cardiomyopathy. J Investig Med 1997;45:542-551.

53. Mettimano M, Romano-Spica V, Ianni A, Specchia ML, Migneco A, Savi L. AGT and AT1R gene polymorphism in hypertensive heart disease. Int J Clin Pract 2002; 56:574-577.

54. Ortlepp JR, Breithardt O, Ohme F, Hanrath P, Hoffmann R. Lack of association among five genetic polymorphisms of the renin-angiotensin system and cardiac hypertrophy in patients with aortic stenosis. Am Heart J 2001;141:671-676.

55. Kauma H, Ikäheimo M, Savoleinen MJ et al. Variants of renin-angiotensin system genes and echocardiographic left ventricular mass. Eur Heart J 1998;19:1109-1117.

56. Shlyakhto EV, Shwartz EI, Nefedova YB et al. Lack of association of the reninangiotensin system genes polymorphisms and left ventricular hypertrophy in hypertension. Blood Press 2001;10:135-141.

57. Beige J, Zilch $\mathrm{O}$, Hohenbleicher $\mathrm{H}$ et al. Genetic variants of the renin-angiotensin system and ambulatory blood pressure in essential hypertension. J Hypertens 1997; 15:503-508.

58. Winnicki M, Somers VK, Accurso V et al. Alpha-adducin Gly460Trp polymorphism, left ventricular mass and plasma renin activity. J Hypertens 2002;20:17711777.

59. Wang AY, Chan JC, Wang M et al. Cardiac hypertrophy and remodeling in relation to ACE and angiotensinogen genes genotypes in Chinese dialysis patients. Kidney Int 2003;63:1899-1907.

60. Kim HS, Lee MM, Oh BH et al. Synergistic effect of angiotensin-converting enzyme and angiotensinogen gene on cardiac hypertrophy. Int J Cardiol 2000;72:151-161.

61. Iwai N, Shimoike H, Ohmichi N, Kinoshita M. Angiotensinogen gene and blood pressure in the Japanese population. Hypertension 1995;25:688-93.

62. Ohmichi N, Iwai N, Maeda K, et al. Genetic basis of left ventricular remodeling after myocardial infacrtion. Int J Cardiol 1996;53:265-272.

63. Wagenaar LJ, Voors AA, Buikema H, van Gilst WH. Angiotensin receptors in the cardiovascular system. Can J Cardiol 2002;18:1331-1339.

64. Ishanov $\mathrm{A}$, Okamoto $\mathrm{H}$, Watanabe $\mathrm{M}$ et al. Angiotensin II type 1 receptor gene polymorphisms in patients with cardiac hypertrophy. Jpn Heart J 1998;39:87-96.

65. Deinum J, van Gool JMG, Kofflard MJM, ten Cate FJ, Danser AHJ. Angiotensin II type 2 receptors and cardiac hypertrophy in women with hypertrophic cardiomyopathy. Hypertension 2001;38:1278-81.
66. Erdmann J, Guse M, Kallisch H, Fleck E, Regitz-Zagrosek V. Novel intronic polymorphism $(+1675 \mathrm{G} / \mathrm{A})$ in the human angiotensin II subtype 2 receptor gene. Hum Mutat 2000;15:487.

67. Schmieder RE, Erdmann J, Delles $C$ et al. Effect of the angiotensin II type 2-receptor gene $(+1675 \mathrm{G} / \mathrm{A})$ on left ventricular structure in humans. J Am Coll Cardiol 2001;37:175-182.

68. Herrmann SM, Nicaud V, Schmidt-Petersen K et al. Angiotensin II type 2 receptor gene polymorphism and cardiovascular phenotypes: the GLAECO and GLAOLD studies. Eur J Heart Fail 2002;4:707-712.

69. White PC. Aldosterone: direct effects on and production by the heart. J Clin Endocrinol Metab 2003;88:2376-2383.

70. Connell JMC, Fraser R, MacKenzie S, Davies E. Is altered adrenal steroid biosynthesis a key intermediate phenotype in hypertension? Hypertension 2003;41:993999.

71. Takai E, Akita H, Kanazawa $\mathrm{K}$ et al. Association between aldosterone synthase (CYP11B2) gene polymorphism and left ventricular volume in patients with dilated cardiomyopathy. Heart 2002;88:649-650.

72. Patel R, Lim DS, Reddy D et al. Variants of trophic factors and expression of cardiac hypertrophy in patients with hypertrophic cardiomyopathy. J Mol Cell Cardiol 2000;32:2369-2377.

73. Kupari M, Hautanen A, Lankinen L et al. Associations between human aldosterone synthase (CYP11B2) gene polymorphisms and left ventricular size, mass, and function. Circulation 1998;97:569-575.

74. Delles C, Erdmann J, Jacobi J et al. Aldosterone synthase (CYP11B2) -344 C/T polymorphism is associated with left ventricular structure in human arterial hypertension. J Am Coll Cardiol 2001;37:878-884.

75. Schunkert H, Hengstenberg C, Holmer SR et al. Lack of association between a polymorphism of the aldosterone synthase gene and left ventricular structure. Circulation 1999;99:2255-2260.

76. Hengstenberg C, Holmer SR, Mayer B et al. Evaluation of the aldosterone synthase (CYP11B2) gene polymorphism in patients with myocardial infarction. Hypertension 2000;35:704-709.

77. Mayosi BM, Keavny B, Watkins H, Farrall M. Measured haplotype analysis of the aldosterone synthase gene and heart size. Eur J Hum Genet 2003;11:395-401.

78. Port JD, Bristow MR. Altered beta-adrenergic receptor gene regulation and signaling in chronic heart failure. J Mol Cell Cardiol 2001;33:887-905.

79. Liggett B. Pharmacogenetics of beta-1-and beta-2-adrenergic receptors. Pharmacology 2000;61:167-73.

80. Small KM, Forbes SL, Rahman FF, Bridges KM, Liggett SB. A four amino acid deletion polymorphism in the third intracellular loop of the human $\alpha_{2 \mathrm{C}}$-adrenergic receptor confers impaired coupling to multiple effectors. J Biol Chem 2000;275: 23059-23064.

81. Small KM, Wagoner LE, Levin AM, Kardia SLR, Liggett SB. Synergistic polymorphisms of $\beta_{1}$ - and $\alpha_{2 c}$-adrenergic receptors and the risk of congestive heart failure. N Engl J Med 2002;347:1135-1142.

82. Mason DA, Moore JD, Green SA, Liggett SB. A gain-of-function polymorphism in a G-protein coupling domain of the human betal-adrenergic receptor. J Biol Chem 1999;274:12670-12674

83. Börjesson M, Magnusson Y, Hjalmarson Å, Andersson B. A novel polymorphism

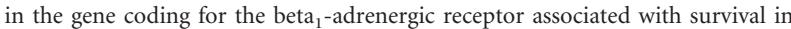
patients with heart failure. Eur Heart J 2000;21:1853-1858.

84. Levin MC, Marullo S, Muntaner O, Andersson B, Magnusson Y. The myocardiumprotective Gly- 49 variant of the $\beta_{1}$-adrenergic receptor exhibits constitutive activity and increased desensitisation and down-regulation. J Biol Chem 2002;277:30429-30435

85. Tesson F, Charron P, Peuchmard $\mathrm{M}$ et al. Characterization of a unique genetic variant in the $\beta_{1}$-adrenoceptor gene and evaluation of its role in idiopathic dilated cardiomyopathy. J Mol Cell Cardiol 1999;31:1025-32.

86. Podlowski S, Wenzel K, Luther HP et al. $\beta_{1}$-Adrenoceptor gene variations: a role in idiopathic dilated cardiomyopathy? J Mol Med 2000;78:87-93.

87. Wagoner LE, Craft LL, Zengel P et al. Polymorphisms of the $\beta_{1}$-adrenergic receptor predict exercise capacity in heart failure. Am Heart J 2002;144:840-846.

88. Stanton T, Inglis GC, Padmanabhan S, Dominiczak AF, Jardine AG, Connell JMC. Variation at the betal-adrenoceptor gene locus affects left ventricular mass in renal failure. J Nephrol 2002;15:512-518.

89. Wenzel K, Felix SB, Bauer D, et al. Novel variants in $3 \mathrm{~kb}$ of $5^{\prime} \mathrm{UTR}$ of the $\beta_{1}$ adrenergic receptor gene $(-93 \mathrm{C}>\mathrm{T},-210 \mathrm{C}>\mathrm{T}$, and $-2146 \mathrm{~T}>\mathrm{C}):-2146 \mathrm{C}$ homozygotes present in patients with idiopathic dilated cardiomyopathy and coronary heart disease. Hum Mutat 2000;16:534

90. Liggett SB, Wagoner LE. Craft LL, Hornung RW, Hoit BD, McIntosh TC. The Ile164 $\beta_{2}$-adrenergic receptor polymorphism adversely affects the outcome of congestive heart failure. J Clin Invest 1998;102:1534-1539. 


\section{Bleumink et al.}

91. Green SA, Cole G, Jacinto M, Innis M, Liggett SB. A polymorphism of the human 2-adrenergic receptor within the fourth transmembrane domain alters ligand binding and functional properties of the receptor. J Biol Chem 1993;268:23116-21.

92. Busjahn A, Li GH, Faulhaber HD et al. $\beta 2$-Adrenergic receptor gene variations, blood pressure, and heart size in normal twins. Hypertension 2000;35:555-560.

93. Green SA, Turki J, Innis M, Liggett SB. Amino-terminal polymorphisms of the human beta 2-adrenergic receptor impart distinct agonist-promoted regulatory properties. Biochemistry 1994;33:9414-9419.

94. Wagoner LE, Craft LL, Singh B et al. Polymorphisms of the $\beta 2$-adrenergic receptor determine exercise capacity in patients with heart failure. Circ Res 2000;86:834840 .

95. Herrmann V, B [dacute] uscher R, Go MM et al. $\beta_{2}$-Adrenergic receptor polymorphisms at codon 16, cardiovascular phenotypes and essential hypertension in whites and African Americans. Am J Hypertens 2000;13:1021-1026.

96. Candy G, Samani N, Norton G et al. Association analysis of $\beta_{2}$ adrenoceptor polymorphisms with hypertension in a Black African population. J Hypertens 2000; 18:167-172.

97. Castellano $\mathrm{M}$, Rossi $\mathrm{F}$, Giacchè $\mathrm{M}$ et al. $\beta_{2}$-Adrenergic receptor gene polymorphism, age, and cardiovascular phenotypes. Hypertension 2003;41:361-367.

98. Krum H, Denver R, Tzanidis A, Martin P. Diagnostic and therapeutic potential of the endothelin system in patients with chronic heart failure. Heart Fail Rev 2001;6:341-352.

99. Charron P, Tesson F, Poirier O et al. Identification of a genetic risk factor for idiopathic dilated cardiomyopathy. Eur Heart J 1999;20:1587-1591.

100. Herrmann SM, Schmidt-Petersen K, Pfeifer J et al. A polymorphism in the endothelin-A receptor gene predicts survival in patients with idiopathic dilated cardiomyopathy. Eur Heart J 2001;22:1948-1953.

101. Lajemi M, Gautier S, Poirier O et al. Endothelin gene variants and aortic and cardiac structure in never-treated hypertensives. Am J Hypertens 2001;14:755-760.

102. Feldman RD. Adrenergic receptor polymorphisms and cardiac function (and dysfunction). A failure to communicate [editorial]? Circulation 2001;103:1042-1043.

103. Colhoun HM, McKeigue PM, Smith GD. Problems of reporting genetic associations with complex outcomes. Lancet 2003;361:865-872.

104. Cardon LR, Palmer LJ. Population stratification and spurious allelic association. Lancet 2003;361:598-604.

105. Odawara M, Matsunuma A, Yamashita K. Mistyping frequency of the angiotensinconverting enzyme gene polymorphism and an improved method for its avoidance. Hum Genet 1997;100:163-166.

106. Brull D, Dhamrait S, Myerson S et al. Bradykinin B2BKR receptor polymorphism and left-ventricular growth response. Lancet 2001;358:1155-1156.

107. Gumprecht J, Zychma M, Grzeszczak W et al. Angiotensin I-converting enzyme and chymase gene polymoprhisms - relationship to left ventricular mass in type 2 diabetes patients. Med Sci Monit 2002;8:CR603-CR606.

108. Densem CG, Hutchinson IV, Yonan N, Brooks NH. Tumour necrosis factor $\alpha$ gene polymorphism: a predisposing factor to non-ischemic myocardial dysfunction? Heart 2002;87:153-155.
109. Ito M, Takahashi H, Fuse K et al. Polymorphisms of tumor necrosis factor- $\alpha$ and interleukin-10 genes in Japanese patients with idiopathic dilated cardiomyopathy. Jpn Heart J 2000;41:183-191.

110. Holweg CTJ, Baan CC, Niesters HGM et al. TGF- $\beta 1$ gene polymorphisms in patients with end-stage heart failure. J Heart Lung Transplant 2001;20:979-984.

111. Hiroi S, Harada H, Nishi H, Satoh M, Nagai R, Kimura A. Polymorphisms in the SOD2 and HLA-DRB1 genes are associated with nonfamial idiopathic dilated cardiomyopathy in Japanese. Biochem Biophys Res Commun 1999;261:332-339.

112. Yamada Y, Ichihara S, Izawa H, Tanaka M, Yokota M. Association of a G ${ }^{994} \rightarrow$ $\mathrm{T}\left(\mathrm{Val}^{279} \rightarrow \mathrm{Phe}\right)$ polymorphism of the plasma platelet-activating factor acetylhydrolase gene with myocardial damage in Japanese patients with nonfamilial hypertrophic cardiomyopathy. J Hum Genet 2001;46:436-441.

113. Ichihara S, Yamada Y, Yokota M. Association of a $\mathrm{G}^{944} \rightarrow \mathrm{T}$ missense mutation in the plasma platelet-activating factor acetylhydrolase gene with genetic susceptibility to nonfamilial dilated cardiomyopathy in Japanese. Circulation 1998;98:18811885

114. Ortlepp JR, Vesper K, Mevissen V et al. Chemokine receptor (CCR2) genotype is associated with myocardial infarction and heart failure in patients under 65 years of age. J Mol Med 2003;29:363-367.

115. McNamara DM, Holubkov R, Postava L et al. Effect of the Asp ${ }^{298}$ variant of endothelial nitric oxide synthase on survival for patients with congestive heart failure. Circulation 2003;107:1598-1602.

116. Economou-Petersen E, Aessopos A, Kladi A et al. Apolipoprotein E $\epsilon 4$ allele as a genetic risk factor for left ventricular failure in homozygous $\beta$-thalassemia. Blood 1998;92:3455-3459.

117. Ferrara M, Matarese SMR, Francese $M$ et al. Role of apolipoprotein E (APOE) polymorphism on left cardiac failure in homozygous $\beta$ thalassaemic patients [letter]. Br J Haematol 2001;114:954-962.

118. Yilmaz H, Isbir T, Ağaçhan B, Aydin M. Is $\epsilon 4$ allele of apolipoprotein E associated with more severe end-organ damage in essential hypertension? Cell Biochem Funct 2001;19:191-195

119. Poch E, González D, Gómez-Angelats E et al. G-protein $\beta_{3}$ subunit gene variant and left ventricular hypertrophy in essential hypertension. Hypertension 2000;35[part 2]:214-218.

120. Semplicini A, Siffert W, Sartori M et al. G protein $\beta_{3}$ subunit gene $825 \mathrm{~T}$ allele is associated with increased left ventricular mass in young subjects with mild hypertension. Am J Hypertens 2001;14:1191-1195.

121. Loh E, Rebbeck TR, Mahoney PD, DeNofrio D, Swain JL, Holmes EW. Common variant in AMPD1 gene predicts improved clinical outcome in patients with heart failure. Circulation 1999;99:1422-1425.

122. Elliott P, McKenna WJ. Hypertrophic cardiomyopathy, Lancet 2004;363:18811891

123. Nabel EG. Cardiovascular disease. N Engl J Med 2003;349:60-72. 